\title{
Diagnostic value of Pentraxin-3 in patients with sepsis and septic shock in accordance with latest sepsis-3 definitions
}

\author{
Sonja Hamed ${ }^{1 \dagger}$, Michael Behnes ${ }^{1 *}$ (D), Dominic Pauly ${ }^{1}$, Dominic Lepiorz', Max Barre ${ }^{1}$, Tobias Becher ${ }^{1}$, \\ Siegfried Lang ${ }^{1}$, Ibrahim Akin ${ }^{1}$, Martin Borggrefe ${ }^{1}$, Thomas Bertsch ${ }^{2}$ and Ursula Hoffmann ${ }^{1}$
}

\begin{abstract}
Background: Pentraxin-3 (PTX-3) is an acute-phase protein involved in inflammatory and infectious processes. This study assesses its diagnostic and prognostic value in patients with sepsis or septic shock in a medical intensive care unit (ICU).

Methods: The study includes 213 ICU patients with clinical criteria of sepsis and septic shock. 77 donors served as controls. Plasma levels of PTX-3, procalcitonin (PCT) and interleukin-6 were measured on day 1, 3 and 8.

Results: PTX-3 correlated with higher lactate levels as well as with APACHE II and SOFA scores $(p=0.0001)$. PTX-3 levels of patients with sepsis or septic shock were consistently significantly higher than in the control group $(p \leq 0.001)$. Plasma levels were able to discriminate sepsis and septic shock significantly on day 1,3 and 8 (range of AUC 0.73-0.92, $p=0.0001$ ). Uniform cut-off levels were defined at $\geq 5 \mathrm{ng} / \mathrm{ml}$ for at least sepsis, $\geq 9 \mathrm{ng} / \mathrm{ml}$ for septic shock $(p=0.0001)$.
\end{abstract}

Conclusion: PTX-3 reveals diagnostic value for sepsis and septic shock during the first week of intensive care treatment, comparable to interleukin-6 according to latest Sepsis-3 definitions.

Trial registration: NCT01535534. Registered 14.02.2012

Keywords: Sepsis, Septic shock, Pentraxin-3, ICU, Biomarkers, Sepsis-3

\section{Background}

Sepsis is a widely common clinical syndrome, caused by a systemic infection and accompanied by consecutive organ failure often leading to a lethal outcome [1-3]. Hence, the early diagnosis and identification of sepsis patients is essential, as early evidence-based treatment and therapeutic interventions are likely to improve survival and decrease in-hospital mortality rates [2, 4-8]. Both the widely used $\mathrm{C}$ reactive protein (CRP) and [9] procalcitonin (PCT) are inconsistent concerning diagnostic capacity [10]. Accordingly, the evaluation of new diagnostic biomarkers discriminating patients with sepsis or septic shock in an early stage is essential, as mortality rates of specifically septic shock are still

\footnotetext{
* Correspondence: michael.behnes@umm.de

${ }^{\dagger}$ Equal contributors

${ }^{1}$ First Department of Medicine, University Medical Centre Mannheim (UMM), Faculty of Medicine Mannheim, University of Heidelberg,

Theodor-Kutzer-Ufer 1-3, Mannheim 68167, Germany

Full list of author information is available at the end of the article
}

unacceptably high despite the developments of modern intensive care medicine.

Pentraxin-3 (PTX-3) is an acute phase protein representing the long pentraxin subfamily [11-13]. Production of PTX-3 is strongly induced by cytokines like interleukin1 , tumor necrosis factor $\alpha(\mathrm{TNF}-\alpha)$ and by toll-like receptor (TLR) agonists, but not by interleukin 6 (IL-6) or interferons $[11,12]$. PTX-3 is expressed in various cells, like dendritic cells, monocytes, endothelial cells or neutrophils during inflammatory processes [13-15]. Several studies found increased PTX-3 expression due to various specific infectious agents such as aspergillus fumigatus, Staphylococcus aureus, pseudomonas aeruginosa, Klebsiella pneumoniae, E. coli, neisseria meningitides, and multiple viruses [16-21]. PTX-3 appears to reveal significant potential as a novel early diagnostic and prognostic biomarker in infectious disorders and septic patients as analyzed in former studies [13-16, 22, 23]. However, the previous studies showed inconsistent study cohorts of different size and composition as well as different follow- 
up periods, not enabling an expressive conclusion considering the role of PTX-3 in these patients [23-31].

Additionally, there are currently no biomarker studies evaluating the diagnostic value of PTX-3 according to the latest Sepsis-3 definitions [3]. Therefore, this study applies these definitions and aims to investigate the diagnostic value of PTX-3 in patients with sepsis and septic shock during the first week of intensive care treatment.

\section{Methods}

\section{Study patients, design and data collection}

The Mannheim Sepsis Study (MaSep, clinicaltrials.gov identifier: NCT01535534) was conducted as a monocentric prospective controlled study at the University Medical Centre Mannheim (UMM), Germany. Patient enrolment started in October 2011. The study was carried out according to the principles of the declaration of Helsinki and was approved by the medical ethics commission II of the Faculty of Medicine Mannheim, University of Heidelberg, Germany. Written informed consent was obtained from each participating patient or their legal representatives. The study was designed to reflect a representative cohort of patients found at an internal intensive care unit (ICU) with a minimum age of 18 years and proven criteria of sepsis or septic shock [32]. Main exclusion criteria were any traumatic or postoperative cause of sepsis development. We enrolled a total of 30 healthy volunteers in addition to 30 hospitalized patients being treated for different medical conditions without any evidence of infection (normal CRP, WBC, body temperature) serving as controls.

At the end of each hospital treatment, two study physicians independently reviewed all available clinical data of the study patients in order to determine each patient's correct disease severity on each day. For the present analysis the latest sepsis-3 definitions of 2016 (i.e. sepsis, septic shock) were applied and all patients were re-classified according to these new definitions [3]. A minor number of patients had to be down classified, as in retrospect; they did not fulfill the criteria for sepsis nor septic shock on day $1(n=17)$. They were therefore additionally merged with the 60 controls. Naturally, over the course of ICU treatment, patients improved or deteriorated. This means a number of patients, initially presenting with septic shock, could improve to sepsis or even better between days 3 and 8 , while patients with sepsis on day 1 could develop a septic shock on day 3 or 8 . Therefore, on days 3 and 8 the distribution of patients per group is different than on day 1 .

The criteria for sepsis and septic shock were as follows [3]: Patients were assigned to the sepsis-group if an increase of the Sequential Organ Failure Assessment (SOFA) score of 2 points or more was observed as a consequence to a present infection. When patients additionally had a persisting hypotension with vasopressor requirement to maintain a mean arterial pressure of at least $65 \mathrm{mmHg}$ and the serum lactate level was greater than $2 \mathrm{mmol} / \mathrm{l}$ despite volume resuscitation, they were classified as septic shock.

In the formerly established criteria, there was an additional definition for severe sepsis, which is now met by the new criteria for sepsis, as well as for the systemic inflammatory response syndrome (SIRS), which was diagnosed if at least two of the following symptoms were present: body temperature $\geq 38{ }^{\circ} \mathrm{C}$ or $\leq 36{ }^{\circ} \mathrm{C}$, heart rate $\geq 90$ beats per minute, tachypnea (respiratory rate $\geq 20$ /min or hyperventilation: $\mathrm{PaCO} 2 \leq 32 \mathrm{mmHg}$ ) and leukocytosis $(\geq 12,000 / \mathrm{cu} \mathrm{mm})$ or leukopenia $(\leq 4000 / \mathrm{cu} \mathrm{mm})$ [33].

According to new guidelines, lactate levels were assessed for all patient groups $[3,34]$. Disease severity on the ICU was documented by the acute physiology and chronic health evaluation II (APACHE II) and the sequential organ failure assessment (SOFA) score [35, 36].

All patient data, such as creatinine levels, hemoglobin, hematocrit, white blood cell count, platelet count, CRP, bilirubin, sodium, potassium, urea, interleukin 6 (IL-6), PCT, body temperature, respiratory rate, heart rate, blood pressure, partial pressure of $\mathrm{O} 2$ and $\mathrm{CO} 2$, bicarbonate, base excess, lactate, $\mathrm{pH}$ value, Glasgow coma scale (GCS) were documented from the patient files. Additionally, prior medical history, age, sex, body weight and the germ spectrum were documented.

Blood samples for PTX-3 measurements were taken within $24 \mathrm{~h}$ after clinical onset of sepsis or septic shock on the ICU (day 1) as well as on day 3 and 8 of ICU treatment. All patients were followed up until 30 days and 6 months after study inclusion by direct telephone visits with the patients or their general practitioners. The main prognostic outcome was all-cause mortality after 30 days and 6 months.

\section{Biomarker measurements}

Blood samples were obtained by venipuncture into serum and ethylenediaminetetraacetic acid (EDTA) monovettes $^{\ominus}$ (SARSTEDT AG \& Co.; Nümbrecht, Germany). Within 30 min all blood samples were centrifuged at $2500 \times$ g at $20^{\circ} \mathrm{C}$ for $10 \mathrm{~min}$. Plasma and serum were separated and aliquoted. The aliquoted samples were cooled down with liquid nitrogen before being stored at $-80{ }^{\circ} \mathrm{C}$ until Analysis.

PTX-3 measurements were performed with the Quantikine ${ }^{\bullet}$ Human Pentraxin 3/TSG-14 Immunoassay (R\&D Systems Inc., Minneapolis, USA) using plasma from EDTA monovettes. IL- 6 and PCT were measured in serum. IL-6 was measured with reagents from Roche Diagnostics (Roche Diagnostics, Mannheim, Germany) 
and PCT was measured with reagents from Thermo Fisher Scientific (Thermo Fisher Scientific Clinical Diagnostics, BRAHMS GmbH, Henningsdorf, Germany). The assays were performed on a Cobas e601 twin module and on a Cobas e602 module (Roche Diagnostics, Mannheim, Germany). Interleukin-6 and PCT measurements were performed at the central laboratory in Nuremberg, Germany.

\section{Statistical analysis}

Statistical analysis was performed with InStat (GraphPad Software) and SPSS software (SPSS Software GmbH). Comparisons between two groups, for instance healthy subjects and patients with sepsis, were performed with the Student's t-test. In case of more than two groups, metric variables were compared by analysis of variance (ANOVA), if applicable. For normally distributed metric data (as tested by the Kolmogorov-Smirnov test), the Student t-test was applied. For variables not normally distributed, the Mann-Whitney U-test was used as a nonparametric test. Spearman's rank correlation for nonparametric data was used to test the association of PTX3 blood levels with medical parameters. Qualitative parameters were analyzed by use of a $2 \times 2$ contingency table and Chi2 test or Fisher's exact test as appropriate. Quantitative data are presented as mean \pm standard error of mean (SEM) or as median and interquartile ranges (IQR) (i.e. 25th to 75th percentiles), depending

Table 1 Baseline characteristics of the Mannheim Sepsis Study (MaSep) at day 1

\begin{tabular}{|c|c|c|c|c|}
\hline & $\begin{array}{l}\text { Controls } \\
(n=77)\end{array}$ & $\begin{array}{l}\text { Sepsis } \\
(n=73)\end{array}$ & $\begin{array}{l}\text { Septic Shock } \\
(n=140)\end{array}$ & $p$-values \\
\hline Age, years (mean, range) & $64(42-87)$ & $65(26-88)$ & $67(39-87)$ & 0.9 \\
\hline \multicolumn{5}{|l|}{ Gender, n (\%) } \\
\hline Male & $42(55)$ & $47(64)$ & $101(72)$ & $<0.001$ \\
\hline Female & $35(45)$ & $26(36)$ & $39(28)$ & 0.1 \\
\hline \multicolumn{5}{|l|}{ Site of infection, n (\%) } \\
\hline Lung & - & $47(64)$ & $84(60)$ & 0.001 \\
\hline Urinary tract & - & $9(12)$ & $12(8)$ & 0.5 \\
\hline Abdominal & - & $10(14)$ & $15(11)$ & 0.3 \\
\hline Central nervous system & - & $0(0)$ & $0(0)$ & - \\
\hline Skin & - & $2(3)$ & $8(6)$ & 0.06 \\
\hline Heart & - & $4(6)$ & $4(3)$ & 1.0 \\
\hline Blood & - & $1(1)$ & $10(7)$ & 0.007 \\
\hline Others & - & $0(0)$ & $7(5)$ & - \\
\hline \multicolumn{5}{|l|}{ Laboratory values, mean \pm SEM } \\
\hline White blood cells $\left(10^{9} / \mathrm{L}\right)$ & - & $16.1 \pm 1.4$ & $18.1 \pm 1.2$ & 0.4 \\
\hline Platelets, (10E9/L) & - & $221 \pm 16.2$ & $169 \pm 9.9$ & 0.01 \\
\hline Bilirubin, mg/dl & - & $1.6 \pm 0.4$ & $3 \pm 0.6$ & 0.004 \\
\hline Lactate mg/dl & - & $2.3 \pm 0.2$ & $3.5 \pm 0.3$ & 0.002 \\
\hline Creatinine, mg/dl & - & $2.4 \pm 0.2$ & $2.8 \pm 0.2$ & 0.05 \\
\hline $\mathrm{C}$ reactive proteine, $\mathrm{mg} / \mathrm{l}$ & - & $186 \pm 12.5$ & $207 \pm 9.5$ & 0.2 \\
\hline Procalcitonin, ng/ml & - & $12.5 \pm 2.7$ & $31 \pm 5.7$ & 0.002 \\
\hline Interleukin 6, pg/ml & - & $16,281 \pm 15,560$ & $6802 \pm 1911$ & $<0.001$ \\
\hline $\mathrm{pCO} 2(\mathrm{mmHg})$ & - & $37.9 \pm 1.6$ & $43.7 \pm 1.6$ & 0.02 \\
\hline Positive blood cultures, n (\%) & - & $28(38)$ & $62(44)$ & $<0.001$ \\
\hline \multicolumn{5}{|l|}{ ICU parameters, mean \pm SEM } \\
\hline ICU days & - & $10 \pm 1.1$ & $14.6 \pm 1.3$ & 0.1 \\
\hline Ventilation days & - & $4.3 \pm 0.9$ & $9.4 \pm 1.1$ & $<0.001$ \\
\hline Catecholamine days & - & $2 \pm 0.5$ & $7.4 \pm 0.6$ & $<0.001$ \\
\hline Renal replacement therapy days & - & $1 \pm 0.3$ & $4.2 \pm 0.7$ & $<0.001$ \\
\hline APACHE II, mean \pm SEM & - & $20.5 \pm 0.9$ & $27.6 \pm 0.6$ & $<0.001$ \\
\hline SOFA score, mean \pm SEM & - & $7.2 \pm 0.4$ & $12.3 \pm 0.3$ & $<0.001$ \\
\hline
\end{tabular}


on the distribution of the data. For qualitative parameters absolute and relative frequencies are presented. A test for linear trend was applied to compare the biomarker levels in the different groups of disease severity. All analyses were exploratory and a two-tailed $p$-value of $<0.05$ was taken as a cut-off for statistical significance.

\section{Diagnostic value of biomarkers}

For C-statistics: To evaluate pre-test discriminative capacities of each biomarker, receiver-operating characteristic (ROC) curve analyses were performed with calculation of area under the curve (AUC) for diagnosis of sepsis and septic shock during the first week of ICU treatment at days 1,3 and 8 for each biomarker. For PTX-3, diagnostic goodness criteria (that is, accuracy, specificity, sensitivity, negative/positive predictive values (NPV/PPV), and relative risk) were calculated. Accuracy was defined as the sum of true positives plus true negatives divided by all measured patients.

\section{Results}

Baseline characteristics are presented in Table 1. A total of 213 patients and 77 healthy controls have been enrolled into the MaSep study. At the time of enrollment, 34\% of patients suffered from sepsis and 66\% from septic shock, respectively. The most common
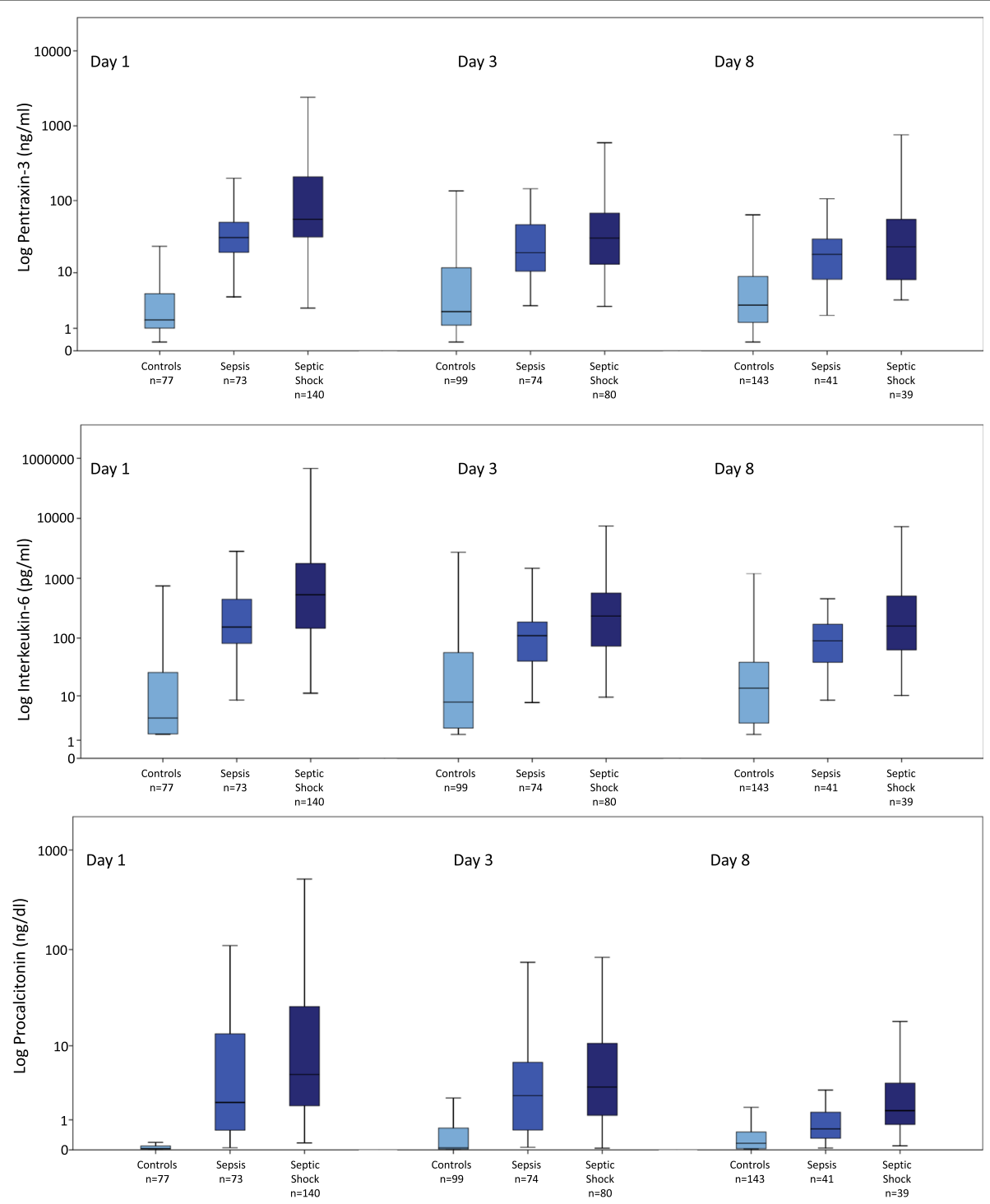

Fig. 1 PTX-3 (top), procalcitonin (PCT, middle) and IL-6 plasma levels (bottom) in patients admitted to an internal ICU with proven criteria of sepsis and septic shock. Left diagrams show results of biomarker measurements at day 1, middle diagrams show results at day 3 and right diagrams show results at day 8. Seventy-seven individuals served as a control group at day 1. Data are presented as medians with 25th and 75th percentiles (boxes) and 5th and 95th percentiles (whiskers) 
site of infection were the lungs (approximately 62\%) and abdomen (12\%).

\section{Distribution of PTX-3 according to latest sepsis-3 definitions}

Figure 1 shows the distribution of PTX-3, IL-6 and PCT in the different groups of disease severity on day 1,3 and 8. On each day of measurement, PTX-3 levels of patients with sepsis as well as levels of patients with septic shock were significantly higher than in the control group $(p \leq 0.001)$. Although overall PTX-3 levels showed a decreasing linear trend from day 1 to day 8 of ICU treatment $(p=0.0001)$, median serum PTX-3 levels in patients with septic shock consistently remained higher than in patients with sepsis throughout the first week of ICU treatment.

Within the control cohort, 17 individuals fulfilled the former criteria for SIRS on day $1\left(\mathrm{n}_{\mathrm{d} 3}=25, \mathrm{n}_{\mathrm{d} 8}=36\right)$. Figure 2 demonstrates the PTX-3 levels in this cohort compared to patients with sepsis. PTX-3 levels on day one were higher in the sepsis cohort (median $31.4 \mathrm{ng} / \mathrm{ml}$ ) compared to the SIRS cohort (median $23.8 \mathrm{ng} / \mathrm{ml}$ ), however not statistically significant $(p>0.05)$. Accordingly, no significant difference was shown on days 3 and 8 between both subgroups.

\section{Univariate correlations of PTX-3 levels}

Statistically significant correlations of PTX-3-levels were shown with the following clinical parameters (Table 2): higher lactate levels $(r=0.36, p<0.0001)$, APACHE II score $(r=0.36, p<0.0001)$, a higher SOFA score $(r=0.36, p<0.0001)$ as well as with a lower mean arterial pressure $(r=-0.25, p<0.0001)$ and higher serum creatinine $(r=0.17, p<0.01)$. There was also a significant association of PTX-3 with the established inflammatory biomarkers IL-6 ( $r=0.37, p<0.0001)$, PCT $(r=0.28, p<0.0001)$, and CRP $(r=0.26, p<0.0001)$.
PTX-3 discriminates sepsis and septic shock according to latest sepsis-3 definitions

C-statistics revealed valuable diagnostic capacity for PTX-3 (Table 3). Diagnostic AUCs for discriminating patients with at least sepsis were statistically significant on each day of measurement ( $p=0.0001)$ (Fig. 3a). PTX-3 levels valuably discriminated the presence of at least sepsis on each day (minimal AUC $=0.82$ ) (Fig. 3a) as well as of septic shock (minimal AUC = 0.73) (Fig. 3b) and was overall comparable to IL-6 and PCT (Table 3).

In addition, CRP also showed statistically significant AUCs to discriminate sepsis and septic shock on each day. However the AUCs of CRP were consistently lower than those of PTX-3 throughout the first week of ICU treatment. The white blood cell count was not able to discriminate sepsis or septic shock on day 1 or 3 and revealed only moderate diagnostic value on day 8 with AUCs below 0.75 (Table 3).

Subsequently, uniform diagnostic cut-offs were defined to diagnose at least sepsis $(\geq 5.0 \mathrm{ng} / \mathrm{ml})$ and septic shock $(\geq 9.0 \mathrm{ng} / \mathrm{ml}$ ) (Table 4$)$, while trying to maintain a sensitivity of at least $70 \%$ on each day of measurement, with focus on the first day to enable an early diagnosis. Specifically for the presence of sepsis, the minimal sensitivity was $92 \%$ with an according negative predictive value of at least $89 \%$, throughout all treatment days 1 , 3 and 8 .

\section{Discussion}

The present study evaluates the diagnostic value of PTX-3 in patients with sepsis and septic shock according to the latest Sepsis-3 definitions during the first week of intensive care treatment. Since sepsis and septic shock are usually diagnosed inadequately and delayed, current guidelines still demand time-dependent risk stratification of each individual patient during intensive care treatment. Accordingly, diagnostic assessment of study

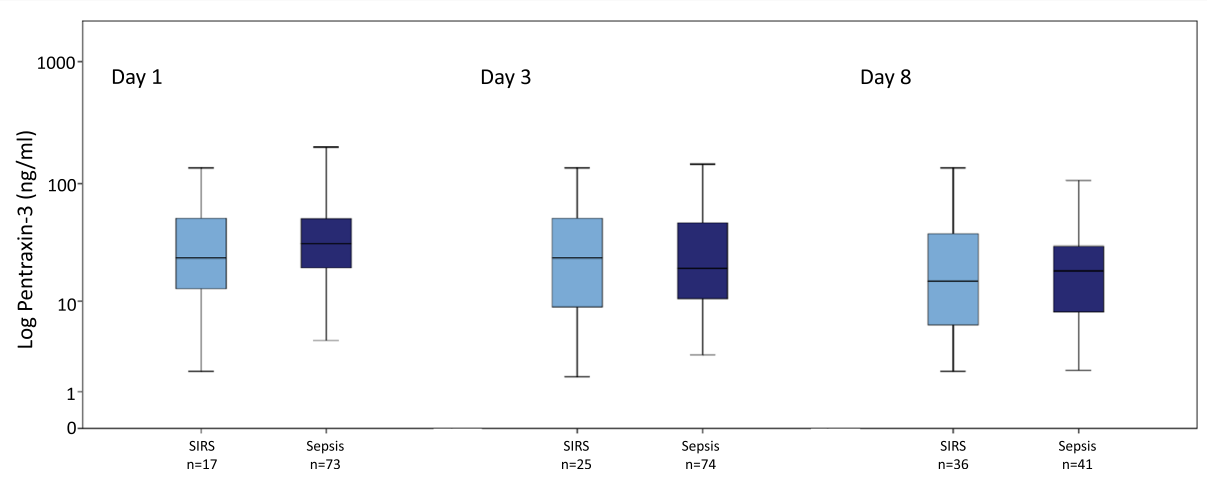

Fig. 2 PTX-3 levels in patients admitted to an internal ICU with proven criteria of SIRS and sepsis on day 1 (left), 3 (middle) and 8 (right). Data are presented as medians with 25th and 75th percentiles (boxes) and 5th and 95th percentiles (whiskers) 
Table 2 Univariate correlations of PTX-3 with laboratory and clinical parameters in all patients $(n=213)$ at day 1

\begin{tabular}{lll}
\hline & $r$ & $p$ value \\
\hline Creatinine & 0.17 & 0.013 \\
Bilirubin & 0.22 & 0.003 \\
Lactate & 0.36 & $<0.001$ \\
Platelets & -0.19 & 0.005 \\
C reactive proteine (CRP) & 0.26 & $<0.001$ \\
Procalcitonin (PCT) & 0.28 & $<0.001$ \\
Interleukin 6 & 0.37 & $<0.001$ \\
Mean arterial pressure & -0.25 & $<0.001$ \\
Mechanical ventilation days & 0.17 & 0.011 \\
Catecholamines days & 0.18 & 0.009 \\
SAPS II score & 0.27 & $<0.001$ \\
APACHE II score & 0.36 & $<0.001$ \\
SOFA score & 0.36 & $<0.001$ \\
\hline
\end{tabular}

patients was performed exemplarily on day 1,3 and 8 of ICU treatment.

The study revealed that valuable and consistent discrimination of sepsis and septic shock was achieved by measurements of PTX-3 plasma levels during days 1, 3, and 8 of ICU treatment, specifically for the presence of at least sepsis. In addition, PTX-3 correlated with disease severity and degree of organ dysfunctions as assessed by clinical scores such as the SOFA score, as has also been described in earlier studies [24, 31]. In line with previous studies, this study confirms that circulating PTX3 concentrations are elevated in sepsis and even higher in septic shock [31]. Consistent with the current observations, multiple previous studies presented significant and valuable AUCs for discriminating sepsis or septic shock from healthy controls [24, 28, 29]. The diagnostic superiority of PTX-3 over PCT or CRP is still under debate, as different studies so far have been inconsistent regarding their diagnostic capacity in patients with sepsis and septic shock, applying different criteria and definitions of the sepsis syndrome [24, 28]. No study is currently available applying the newest Sepsis-3 definitions for novel biomarker analyses.

In contrast to previous studies, the present one aimed to evaluate the potential diagnostic value of PTX-3 in a real-life setting during the first week of treatment on a medical ICU, representing the most critical time frame of patients suffering from sepsis or septic shock [5, 6, 37]. Combining PTX-3 with established biomarkers, such as IL-6, might be of additional value for the discrimination of sepsis and septic shock. Notably, the presented detailed correlations and comparisons of PTX-3 with other established clinical parameters have only scarcely been described yet [31]. The ongoing systemic activation of inflammatory biomarkers such as CRP, interleukin-6 and PCT during sepsis and septic shock may be an explanation of their correlation with PTX-3 levels in affected patients [38, 39]. PTX3 itself is known to be induced by several cytokines

Table 3 Discriminative capacitites of biomarkers for diagnosis of sepsis severity at days 1, 3 and 8 of ICU treatment, analyzed as area under the curves (AUCs (95\% Cl))

\begin{tabular}{|c|c|c|c|c|c|}
\hline & Pentraxin-3 & Interleukin-6 & Procalcitonin & CRP & White blood cells \\
\hline \multicolumn{6}{|l|}{ Day 1} \\
\hline $\begin{array}{l}\geq \text { Sepsis } \\
(n=213)\end{array}$ & $\begin{array}{l}0.92(0.87-0.97) \\
p=0.0001\end{array}$ & $\begin{array}{l}0.91(0.86-0.95) \\
p=0.0001\end{array}$ & $\begin{array}{l}0.92(0.88-0.97) \\
p=0.0001\end{array}$ & $\begin{array}{l}0.82(0.72-0.91) \\
p=0.0001\end{array}$ & $\begin{array}{l}0.59(0.46-0.72) \\
p=0.2\end{array}$ \\
\hline $\begin{array}{l}\text { Septic shock } \\
(n=140)\end{array}$ & $\begin{array}{l}0.81(0.77-0.86) \\
p=0.0001\end{array}$ & $\begin{array}{l}0.81(0.76-0.85) \\
p=0.0001\end{array}$ & $\begin{array}{l}0.79(0.74-0.84) \\
p=0.0001\end{array}$ & $\begin{array}{l}0.61(0.53-0.68) \\
p=0.008\end{array}$ & $\begin{array}{l}0.55(0.47-0.62) \\
p=0.2\end{array}$ \\
\hline \multicolumn{6}{|c|}{ Day 1: controls $n=77$; sepsis $n=73$; septic shock $n=140$. } \\
\hline \multicolumn{6}{|l|}{ Day 3} \\
\hline $\begin{array}{l}\geq \text { Sepsis } \\
(n=154)\end{array}$ & $\begin{array}{l}0.84(0.79-0.90) \\
p=0.0001\end{array}$ & $\begin{array}{l}0.84(0.78-0.89) \\
p=0.0001\end{array}$ & $\begin{array}{l}0.84(0.78-0.90) \\
p=0.0001\end{array}$ & $\begin{array}{l}0.70(0.60-0.79) \\
p=0.0001\end{array}$ & $\begin{array}{l}0.53(0.42-0.63) \\
p=0.6\end{array}$ \\
\hline $\begin{array}{l}\text { Septic shock } \\
(n=80)\end{array}$ & $\begin{array}{l}0.73(0.67-0.80) \\
p=0.0001\end{array}$ & $\begin{array}{l}0.79(0.73-0.85) \\
p=0.0001\end{array}$ & $\begin{array}{l}0.74(0.68-0.80) \\
p=0.0001\end{array}$ & $\begin{array}{l}0.69(0.61-0.76) \\
p=0.001\end{array}$ & $\begin{array}{l}0.54(0.46-0.63) \\
p=0.3\end{array}$ \\
\hline \multicolumn{6}{|c|}{ Day 3: controls $n=99$; sepsis $n=74$; septic shock $n=80$. } \\
\hline \multicolumn{6}{|l|}{ Day 8} \\
\hline $\begin{array}{l}\geq \text { Sepsis } \\
(n=80)\end{array}$ & $\begin{array}{l}0.82(0.77-0.88) \\
p=0.0001\end{array}$ & $\begin{array}{l}0.83(0.77-0.88) \\
p=0.0001\end{array}$ & $\begin{array}{l}0.79(0.74-0.85) \\
p=0.0001\end{array}$ & $\begin{array}{l}0.74(0.66-0.82) \\
p=0.0001\end{array}$ & $\begin{array}{l}0.66(0.57-0.75) \\
p=0.001\end{array}$ \\
\hline $\begin{array}{l}\text { Septic shock } \\
(n=39)\end{array}$ & $\begin{array}{l}0.79(0.72-0.85) \\
p=0.0001\end{array}$ & $\begin{array}{l}0.81(0.75-0.88) \\
p=0.0001\end{array}$ & $\begin{array}{l}0.81(0.75-0.87) \\
p=0.0001\end{array}$ & $\begin{array}{l}0.70(0.60-0.79) \\
p=0.0001\end{array}$ & $\begin{array}{l}0.74(0.65-0.83) \\
p=0.0001\end{array}$ \\
\hline
\end{tabular}

Day 8: controls $n=143$; sepsis $n=41$; septic shock $n=39$. 

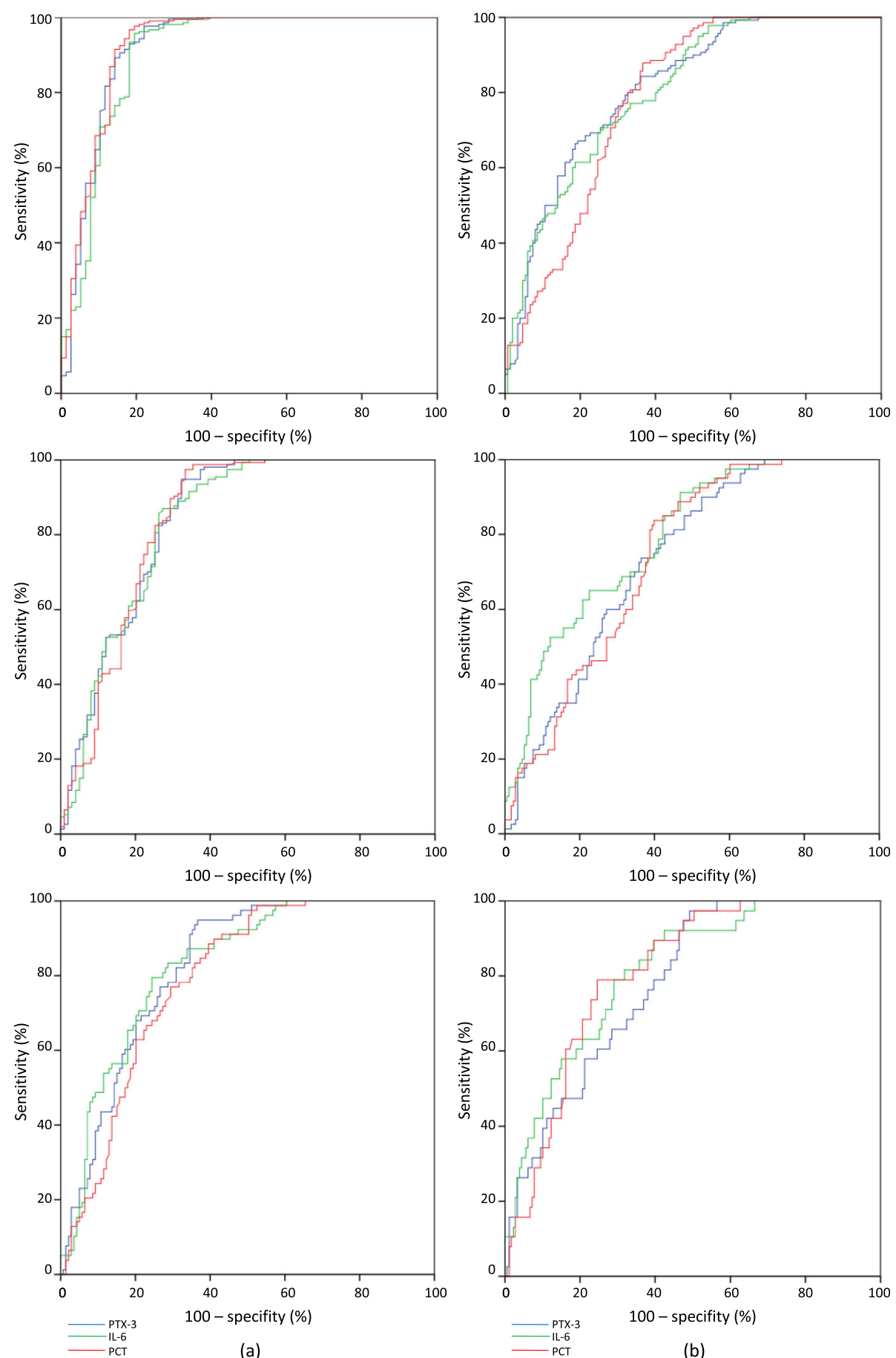

Fig. 3 Receiver-operating characteristic (ROC) curves revealing valuable discrimination of patients with sepsis (a) and septic shock (b) by serum levels of PTX-3, IL-6 and PCT on day 1, 3 and 8 (from top to bottom)

leading to a rapid synthesis in-vitro [11, 12]. Specifically the stimulation by interleukin-1 and TNF- $\alpha$ was shown to increase plasma levels of PTX-3. This effect was shown in various cells and inflammatory steps, such as during the initial phase of inflammation by recognizing pathogens and activation of the complement pathway, thus allowing an approach to explain the early elevated PTX-3 plasma levels in patients with infection [11, 12, 23].

PTX-3 levels revealed no significant difference between patients with SIRS and sepsis in the present cohort. Previous studies measured PTX-3 levels in both 
Table 4 Diagnostic goodness criteria of Pentraxin-3 for diagnosis of sepsis and septic shock during the first week of ICU treatment

\begin{tabular}{|c|c|c|c|c|c|c|c|c|c|}
\hline & AUC & $\begin{array}{l}\text { cutoff } \\
\text { (ng/ml) }\end{array}$ & $\begin{array}{l}\text { accuracy } \\
(\%)\end{array}$ & $\begin{array}{l}\text { sensitivity } \\
(\%)\end{array}$ & $\begin{array}{l}\text { specificity } \\
(\%)\end{array}$ & $\begin{array}{l}\text { PPV } \\
(\%)\end{array}$ & $\begin{array}{l}\text { NPV } \\
(\%)\end{array}$ & relative risk & $p$ value \\
\hline \multicolumn{10}{|l|}{ Day 1} \\
\hline$\geq$ Sepsis & 0.92 & 5 & 92 & 98 & 79 & 92 & 93 & 13.6 & 0.0001 \\
\hline$\geq$ Septic shock & 0.81 & 9 & 68 & 93 & 45 & 61 & 87 & 4.8 & 0.0001 \\
\hline \multicolumn{10}{|l|}{ Day 3} \\
\hline$\geq$ Sepsis & 0.84 & 5 & 84 & 95 & 67 & 82 & 89 & 7.6 & 0.0001 \\
\hline$\geq$ Septic shock & 0.73 & 9 & 61 & 85 & 50 & 44 & 88 & 3.6 & 0.0001 \\
\hline \multicolumn{10}{|l|}{ Day 8} \\
\hline$\geq$ Sepsis & 0.82 & 5 & 74 & 92 & 64 & 59 & 94 & 9.4 & 0.0001 \\
\hline$\geq$ Septic shock & 0.79 & 9 & 66 & 72 & 65 & 31 & 92 & 3.6 & 0.0001 \\
\hline
\end{tabular}

AUC Area under curve, PPV and NPV positive and negative predictive values

groups, however did not compare the values for statistical significance [24]. Additionally it should be noted, that SIRS is considered inadequately specific and sensitive and is no longer part of the sepsis definitions [3].

The strengths of the present study were its prospective character, augmenting the current knowledge about PTX-3 by evaluating its diagnostic capacity at different time points of the first week of ICU treatment. Additionally, this study provides the first analysis of PTX-3 within the individual subgroups sepsis and septic shock as classified by implementing the recently updated sepsis-3 definitions [3]. It is important to identify these high risk patients as they are endangered of fatal outcome even within the following months after hospital discharge [38]. Novel biomarkers such as PTX-3 in combination with established ones such as IL-6 might improve the individual time-dependent risk-stratification of patients with sepsis or septic shock.

\section{Limitations}

The present study was performed as a single centre study. Analyses were not blinded to white blood cells and CRP, as both are used in daily routine by the practicing clinicians. After retrospective re-evaluation of main diagnoses, a minor part of the patients was downgraded to controls. Only patients with an infection and an increase in SOFA Score were included in the study, not allowing a statement on the differentiation between an infection without increase in SOFA score and patients with sepsis. Upcoming randomised controlled multi-centre studies might verify the results of the present study.

\section{Conclusions}

In summary, PTX-3 valuably discriminates the different stages of sepsis severity during the first week of intensive care treatment according to latest Sepsis-3 definitions.

\section{Key points}

- PTX-3 was evaluated in 213 medical ICU patients suspected to suffer from at least sepsis.

- PTX-3 discriminates valuably sepsis and septic shock from healthy controls corresponding to uniform cutoff levels.

- PTX-3 was evaluated according to the latest Sepsis-3 definitions.

\section{Abbreviations}

APACHE: Acute Physiology And Chronic Health Evaluation; AUC: Area under the curve; CRP: C - reactive protein; ICU: Intensive care unit; IL-6: Interleukin-6; IQR: Interquartile range; PCT: Procalcitonin; PTX-3: Pentraxin-3; ROC: Receiveroperating characteristic; SIRS: Systemic inflammatory response syndrome; SOFA: Sepsis-related Organ Failure Assessment; WBC: White blood cells

\section{Acknowledgements}

Supported by the DZHK (Deutsches Zentrum für Herz-Kreislauf-Forschung German Centre for Cardiovascular Research) and by the BMBF (German Ministry of Education and Research).

Funding

Not applicable.

\section{Availability of data and materials}

The datasets used and/or analysed during the current study are available from the corresponding author on reasonable request.

\section{Authors' contributions}

SH participated in the study design and coordination, data acquisition and analysis, carried out the immunoassays, performed statistical analysis and interpretation and drafted the manuscript. MBe conceived the study, participated in its design and coordination, performed statistical analysis, participated in data analysis and interpretation and drafted the manuscript. $D L$ and DP participated in data acquisition and analysis and carried out the immunoassays. MBa helped with statistical analysis. TBec participated in data analysis and interpretation, and helped to revise the manuscript for important intellectual content. SL carried out the immunoassays, performed statistical analysis, participated in data analysis and interpretation, and helped to draft and revise the manuscript for important intellectual content. IA participated in the study conception and design, interpretation of data and critically revised the manuscript for important intellectual content. MBo participated in the study design and coordination and helped to draft and revise the manuscript for important intellectual content. TBer carried out the immunoassays, participated in data analysis and interpretation and helped to draft the manuscript. UH conceived the study, participated in its design and coordination, participated in data analysis and interpretation and helped to draft and 
revise the manuscript for important intellectual content. All authors read and approved the final manuscript.

\section{Ethics approval and consent to participate}

The study was carried out according to the principles of the declaration of Helsinki and was approved by the medical ethics commission II of the Faculty of Medicine Mannheim, University of Heidelberg, Germany. Written informed consent was obtained from each participating patient or their legal representatives.

\section{Consent for publication}

Written informed consent was obtained from each participating patient or their legal representatives.

\section{Competing interests}

The authors declare that they have no competing interests.

\section{Publisher's Note}

Springer Nature remains neutral with regard to jurisdictional claims in published maps and institutional affiliations.

\section{Author details}

'First Department of Medicine, University Medical Centre Mannheim (UMM), Faculty of Medicine Mannheim, University of Heidelberg,

Theodor-Kutzer-Ufer 1-3, Mannheim 68167, Germany. ${ }^{2}$ Institute of Clinical Chemistry, Laboratory Medicine and Transfusion Medicine, General Hospital Nuremberg, Paracelsus Medical University, Nuremberg, Germany.

\section{Received: 8 April 2017 Accepted: 18 July 2017}

\section{Published online: 09 August 2017}

\section{References}

1. Wheeler AP, Bernard GR. Treating patients with severe sepsis. New Engl J Med. 1999;340(3):207-14.

2. Cohen J, Vincent J-L, Adhikari NKJ, Machado FR, Angus DC, Calandra T, et al. Sepsis: a roadmap for future research. Lancet Infect Dis. 2015;15(5):581-614.

3. Singer $M$, Deutschman CS, Seymour $C$, et al. The third international consensus definitions for sepsis and septic shock (sepsis-3). JAMA. 2016: 315(8):801-10.

4. Levy MM, Artigas A, Phillips GS, Rhodes A, Beale R, Osborn T, et al. Outcomes of the surviving sepsis campaign in intensive care units in the USA and Europe: a prospective cohort study. Lancet Infect Dis. 2012;12:919-24.

5. Dellinger RP, Levy MM, Rhodes A, Annane D, Gerlach H, Opal SM, et al. Surviving sepsis campaign: international guidelines for management of severe sepsis and septic shock: 2012. Crit Care Med. 2013:41:580-637.

6. Levy MM, Dellinger RP, Townsend SR, Linde-Zwirble WT, Marshall JC, Bion $\mathrm{J}$, et al. The surviving sepsis campaign: results of an international guidelinebased performance improvement program targeting severe sepsis. Intensive Care Med. 2010;36:222-31.

7. Bloos F, Reinhart K. Rapid diagnosis of sepsis. Virulence. 2014;5:154-60

8. Dellinger RP, Levy MM, Rhodes A, Annane D, Gerlach H, Opal SM, et al. Surviving sepsis campaign: international guidelines for management of severe sepsis and septic shock, 2012. Intensive Care Med. 2012;39(2):165-228.

9. Silvestre J, Povoa P, Coelho L, Almeida E, Moreira P, Fernandes A, et al. Is Creactive protein a good prognostic marker in septic patients? Intensive Care Med. 2009:35(5):909-13.

10. Kibe S, Adams K, Barlow G. Diagnostic and prognostic biomarkers of sepsis in critical care. J Antimicrob Chemother. 2011;66:33-40.

11. Breviarios F, Aniellos EM, Golay J, Bottazzis B, Bairochll A, Sacconell S, et al. Interleukin-1-inducible genes in endothelial cells. J Biol Chem. 1992;267:22190-7.

12. Lee GW, Lee TH, Vileek J. TSG-14, a tumor necrosis factor- and IL-1-inducible protein, is a novel member of the Pentaxin family of acute phase proteins. J Immunol. 1993;150:1804-12.

13. Mantovani A, Garlanda C, Doni A, Bottazzi B. Pentraxins in innate immunity: from C-reactive protein to the long pentraxin PTX3. J Clin Immunol. 2008:28:1-13.

14. Garlanda C, Bottazzi B, Bastone A, Mantovani A. Pentraxins at the crossroads between innate immunity, inflammation, matrix deposition, and female fertility. Annu Rev Immunol. 2005;23:337-66.

15. Bottazzi B, Garlanda C, Cotena A, Moalli F, Jaillon S, Deban L, et al. The long pentraxin PTX3 as a prototypic humoral pattern recognition receptor: interplay with cellular innate immunity. Immunol Rev. 2009;227:9-18.
16. Moalli F, Jaillon S, Inforzato A, Sironi M, Bottazzi B, Mantovani A, et al. Pathogen recognition by the long pentraxin PTX3. J Biomed Biotechnol. 2011;2011:830421.

17. Reading PC, Bozza S, Gilbertson B, Tate M, Moretti S, Job ER, et al. Antiviral activity of the long chain Pentraxin PTX3 against influenza viruses. Immunol. 2008;180(5):3391-8.

18. Garlanda C, Hirsch E, Bozza S, Salustri A, De Acetis M, Nota R, et al. Nonredundant role of the long pentraxin PTX3 in anti-fungal innate immune response. Nature. 2002;420(6912):182-6.

19. Jaillon S, Moalli F, Ragnarsdottir B, Bonavita E, Puthia M, Riva F, et al. The Humoral pattern recognition molecule PTX3 is a key component of innate immunity against urinary tract infection. Immunity. 2014;40(4):621-32.

20. Bottazzi B, Santini L, Savino S, Giuliani MM, Dueñas Díez Al, Mancuso G, et al. Recognition of Neisseria meningitidis by the long Pentraxin PTX3 and its role as an endogenous adjuvant. PLoS One. 2015;10(3):e0120807.

21. Bottazzi B, Inforzato A, Messa M, Barbagallo M, Magrini E, Garlanda C, et al. The pentraxins PTX3 and SAP in innate immunity, regulation of inflammation and tissue remodelling. J Hepatol. 2016;64(6):1416-27.

22. Cuello F, Shankar-Hari M, Mayr U, Yin X, Marshall M, Suna G, et al. Redox state of Pentraxin 3 as a novel biomarker for resolution of inflammation and survival in sepsis. Mol Cell Proteomics. 2014;13(10):2545-57.

23. Liu S, Qu X, Liu F, Wang C. Pentraxin 3 as a prognostic biomarker in patients with systemic inflammation or infection. Mediat Inflamm. 2014;2014:421429.

24. Muller B, Peri G. Doni a, Torri V, Landmann R, Bottazzi B, et al. circulating levels of the long pentraxin PTX3 correlate with severity of infection in critically ill patients. Crit Care Med. 2001;29:1404-7.

25. Mauri T, Bellani G, Patroniti NA, Coppadoro A, Peri G, Cuccovillo I, et al. Persisting high levels of plasma pentraxin 3 over the first days after severe sepsis and septic shock onset are associated with mortality. Intensive Care Med. 2010;36:621-9.

26. De Kruif MD, Limper M, Sierhuis K, Wagenaar JFP, Spek CA, Garlanda C, et al. PTX3 predicts severe disease in febrile patients at the emergency department. J Inf Secur. 2009;60:122-7.

27. Huttunen R, Hurme M, Aittoniemi J, Huhtala H, Vuento R, Laine J, et al. High plasma level of long pentraxin 3 (PTX3) is associated with fatal disease in bacteremic patients: a prospective cohort study. PLoS One. 2011;6(3): e17653.

28. Uusitalo-Seppala R, Huttunen R, Aittoniemi J, Koskinen P, Leino A, Vahlberg $T$, et al. Pentraxin 3 (PTX3) is associated with severe sepsis and fatal disease in emergency room patients with suspected infection: a prospective cohort study. PLoS One. 2013;8(1):e53661.

29. Bastrup-Birk S, Skjoedt MO, Munthe-Fog L, Strom JJ, Ma YJ, Garred P. Pentraxin-3 serum levels are associated with disease severity and mortality in patients with systemic inflammatory response syndrome. PLoS One. 2013;8(9):e73119.

30. Bastrup-Birk S, Munthe-Fog L, Skjoedt MO, Ma YJ, Nielsen H, Køber L, et al. Pentraxin-3 level at admission is a strong predictor of short-term mortality in a community-based hospital setting. J Intern Med. 2015;277(5):562-72.

31. Caironi P, Masson S, Mauri T, Bottazzi B, Leone R, Magnoli M, et al. Pentraxin 3 in patients with severe sepsis or shock: the ALBIOS trial. Eur J Clin Investig. 2017;47(1):73-83.

32. Behnes M, Bertsch T, Lepiorz D, Lang S, Trinkmann F, Brueckmann M, et al. Diagnostic and prognostic utility of soluble CD 14 subtype (presepsin) for severe sepsis and septic shock during the first week of intensive care treatment. Crit Care Med. 2014;18(507):1-13.

33. Bone RC, Balk RA, Cerra FB, Dellinger RP, Fein AM, Knaus WA, et al. American College of Chest Physicians/Society of Critical Care Medicine consensus conference: definitions for sepsis and organ failure and guidelines for the use of innovative therapies in sepsis. Chest. 1992;101(6):1644-55.

34. Shankar-Hari M, Phillips GS, Levy ML, et al. Developing a new definition and assessing new clinical criteria for septic shock: for the third international consensus definitions for sepsis and septic shock (sepsis-3). JAMA. 2016;315(8):775-87.

35. Knaus W, Draper E, Wagner D, Zimmerman J. APACHE II: a severity of disease classification system. Crit Care Med. 1985:13:818-29.

36. Vincent JL, Moreno R, Takala J, Willatts S, De Mendonça A, Bruining H, et al. The SOFA (sepsis related organ failure assessment) score to describe organ/ dysfunction/failure. On behalf of the working group on sepsis-related problems of the European Society of Intensive Care Medicine. Intensive Care Med. 1996;22(7):707-10. 
37. Rivers E, Nguyen B, Havstad S, Ressler J, Muzzin A, Knoblich B, et al. Early goal-directed therapy in the treatment of severe sepsis and septic shock. N Engl J Med. 2001;345(19):1368-77.

38. Angus DC, van der Poll T. Severe sepsis and septic shock. N Engl J Med. 2013;369:840-51.

39. Henriquez-Camacho C, Losa J. Biomarkers for sepsis. Biomed Res Int 2014;2014:547818.

Submit your next manuscript to BioMed Central and we will help you at every step:

- We accept pre-submission inquiries

- Our selector tool helps you to find the most relevant journal

- We provide round the clock customer support

- Convenient online submission

- Thorough peer review

- Inclusion in PubMed and all major indexing services

- Maximum visibility for your research

Submit your manuscript at www.biomedcentral.com/submit
Biomed Central 